\title{
Editorial: Impacts of Marine Litter
}

\author{
${\text { Luisa Galgani }{ }^{1 *} \text {, Ricardo Beiras }}^{2 *}$, François Galgani ${ }^{3 *}$, Cristina Panti ${ }^{14 *}$ and Angel Borja ${ }^{5 *}$ \\ ${ }^{1}$ Department of Biotechnology, Chemistry and Pharmacy, University of Siena, Siena, Italy, ${ }^{2}$ Department of Ecology and \\ Animal Biology, University of Vigo, Vigo, Spain, ${ }^{3}$ Institut Français de Recherche pour l' Exploitation de la Mer (IFREMER), \\ Brest, France, ${ }^{4}$ Department of Environment, Earth and Physical Sciences, University of Siena, Siena, Italy, ${ }^{5}$ Centro \\ Tecnológico Experto en Innovación Marina y Alimentaria (AZTI), Pasaia, Spain
}

Keywords: plastics, nanoplastics, microplastics, environmental regulation, ecotoxicology, aquatic biota

\section{Editorial on the Research Topic}

\author{
Impacts of Marine Litter
}

\section{INTRODUCTION: MOTIVATION AND SUBTOPICS}

Marine litter is a global environmental concern. Between $61 \%$ and $87 \%$ of this litter is plastics (Barboza et al., 2019; Tekman et al., 2019). In 2010 alone, the amount of plastics entering the oceans varied between 4.8 million and 12.7 million metric tons (Jambeck et al., 2015), contributing to an estimated total abundance of at least 5 trillion particles (Eriksen et al., 2014). In 2017, 348 million tons of plastics were produced globally (PlasticsEurope, 2018) and in the next two decades, the amount of plastics produced is expected to double (Geyer et al., 2017).

Continental plastic litter enters the ocean largely through storm-water runoff, is dumped on shorelines during recreational activities or directly discharged at sea from ships (Walker et al., 2019). The deep-sea floor is probably the final global sink for most marine litter that is not decomposed or fractionated to the nanosize (Angiolillo, 2019). However, long-term data are scarce and do not show any clear or significant trend with regards to variations in debris quantities (Maes et al., 2018). In many coastal countries, mismanagement of solid waste has caused between $1.7 \%$ and $4.6 \%$ of the total plastic waste generated to end up in the sea (Hoornweg and BhadaTata, 2012; Jambeck et al., 2015). Despite initiatives to monitor and reduce marine litter, such as from United Nations Environmental Programme (UNEP), the G20, and G7, the European Marine Strategy Framework Directive (European Commission, 2008) and action plans from the Regional Seas Conventions (e.g., OSPAR Regional Action Plan for Marine Litter; UNEP/MAP-Barcelona Convention Regional Plan on Marine Litter Management in the Mediterranean), harm is still far from being understood. Moreover, standardization, and harmonization of sampling techniques, result units and metrics is needed to achieve reliable monitoring and assessment, and threshold values of good/not good status are still at an incipient stage, since ecotoxicological information on the effects of the smaller fractions of plastic litter, microplastics and nanoplastics, in the environment and on aquatic organisms is scarce (Gall and Thompson, 2015; De Sá et al., 2018; Ogonowski et al., 2018).

The coastal landscape is frequently impacted by marine litter that impairs recreational uses and causes a loss of touristic value. Beyond the aesthetic impact, marine litter also bears potential economic implications to maritime activities, such as fisheries and the aquaculture sectors (UNEP, 2014). It may also affect the marine environment and the different ecosystem components (Gall and Thompson, 2015; Rochman et al., 2016; Galloway et al., 2017; Barboza et al., 2019). First, solid particles are ingested by fauna; whereas most of the litter will be excreted, some particles may remain in the stomach undigested, including seafood (Rochman et al., 2015). Large differences among taxa, resulting from differences in size and feeding habits, have been described (Kühn et al., 2015; Bour et al., 2018; Fossi et al., 2018). Many studies have focused on selected species such as seabirds or sea turtles which have even been proposed as bioindicators of oceanic plastic pollution (Bonanno and Orlando-Bonaca, 2018; Fossi et al., 2018) because they feed exclusively at sea, they 
show a non-selective surface foraging, and in certain populations most individuals present plastic debris in their stomachs (Wilcox et al., 2015; Domènech et al., 2019). Second, plastic litter can represent a relevant source of chemical additives, some of them with suspected endocrine disrupting action, that easily leach into the water since they are not bound to the polymeric chains and become available to the estuarine and marine fauna (Hermabessiere et al., 2017). Third, intentionally or accidentally discarded fishing gears pose special risks for large, air-breathing marine animals, including endangered species, which get entangled in the nets (Lusher et al., 2018). Conventional plastics are non-biodegradable and they may persist in the environment for hundreds of years but also because of hydrodynamics and exposure to light, they may fragment into small particles readily taken up by marine organisms. Microplastics and nanoplastics are of particular concern: ingested by even the smallest zooplankton species they can transfer hydrophobic pollutants (and plastic additives) into the trophic webs, although thermodynamic models and experimental data provide conflicting results and more research is needed in this field (Beiras et al., 2018; Burns and Boxall, 2018; Ogonowski et al., 2018). Finally, plastic at sea may transport alien species over long distances or act as substratum for vagile and epistratum benthos, providing a support to colonization (Casabianca et al., 2019).

This Research Topic includes, as yet, 13 papers covering broad oceanic aspects of litter: development of methods, distribution in different species and marine areas, ingestion of plastic, toxicity of plastic associated chemicals, and policies dedicated to reduction measures of marine litter. The impacts related to marine litter have been evaluated from ecological, ecotoxicological, economic and social perspectives, identifying four major subtopics for the papers featured:

1. Sources of marine litter and environmental distribution and sinks: surveys in water, sediments, coast and biota

2. Experimental approaches

3. Impacts on marine organisms: macro-, meio-, and microfauna related to plastics and plastics' associated contaminants 4. Regulations.

\section{SUMMARY OF THE PAPERS}

In this Research Topic, studies considering sources and distributions of marine litter (subtopic 1) span over awide geographic area and different environmental compartments, presenting results from surveys in water, beaches, sediments and biota.

Interactions between species and litter were reviewed for the South East Pacific, indicating the importance of entanglement, microplastic ingestion and the higher sensitivity of sea turtles to marine litter (Thiel et al.). In the North Atlantic, a much higher occurrence of microplastic fragments than previously reported was found in the gut contents of mesopelagic fishes (Wieczorek et al.). Regional surveys suggest that land-based inputs of plastics are to be reconducted to different levels of coastal anthropogenic pressure and population growth. In the Red Sea, low plastic waste was found in surface waters suggesting reduced land-based inputs from the coastal environment (Martí et al.). In Brazil, the nature and predominance of beach litter were directly related to beach users, with less urbanized beaches showing smaller quantities of anthropogenic litter (Araújo et al.). In an urban estuary in Tasmania, the type, distribution and abundance of microplastics observed closely matched data on increasing plastic production, coastal population growth, and proximity to urban water outflows (Willis et al.). Some of the studies highlighted the importance of fibers as part of microplastics with evidence of their non-anthropic origin (Martí et al.; Willis et al.; Wieczorek et al.), but also indicated the need of a careful assessment of the amount of fibers in environmental samples that could be biased by atmospheric contamination while conducting the laboratory analysis (Willis et al.).

Methods were also addressed (subtopic 2) with a review on constraints and priorities for conducting experimental exposures of marine wildlife to microplastics (Paul-Pont et al.).

Impacts of marine litter and marine plastics can be varied and concurrent, arising from entanglement, ingestion, and leaching of plastic-associated contaminants and additives (subtopic 3). In marine fauna, negative effects of marine litter are documented on over 1,400 species and depend on a multiplicity of cofactors that need to be considered when developing management plans for the conservation of ecosystems and biodiversity (Fossi et al.). Five studies describe the release of chemicals and their ecotoxicological effects on marine biota (subtopic 3), including two bivalve species (O'Donovan et al.; Pittura et al.), one crustacean (Thaysen et al.), one annelid species (Gomiero et al.), seabirds and cetaceans (Fossi et al.), indicating that plastics as vectors for organic pollutants may add up to other environmental and anthropic stressors and potentially alter survival rate and reproductive success. Clearly, action modes and toxicological pathways, also considering transcriptional activity, differ according to pollutants. In one freshwater species, significant adverse effects of leachates from expanded polystyrene were detected (Thaysen et al.).

In terms of management (subtopic 4), the role of regulation, public perception and social license to operate in managing waste that enters the ocean were discussed (Vince and Hardesty). More specific case studies on paraffins were also reviewed in the framework of environmental policies, suggesting for regulatory measures (Suaria et al.).

\section{KNOWLEDGE GAPS FILLED, PERSPECTIVES AND CONCLUSIONS}

Overall, this Research Topic provides a panel of various aspects of the impacts of marine litter and plastics, and will largely support more research toward a better understanding of any harm caused by any material at all levels of biological organization. Through this platform, this Research Topic also encourages a discussion forum to better understand all potential effects caused by marine litter, both to marine organisms as well as to the whole marine/estuarine environment and communities, and to propose new strategies of intervention, for prevention, mitigation, and monitoring. 
Several gaps still need to be covered, from the harmonization of methodological approaches to study marine litter in different environmental compartments (i.e., sea surface, sea floor, water column) to the evaluation of the effects on biota. Moreover, the impact of marine litter and, in particular, microplastics and nanoplastics, on human health is still largely debated and a more focused research needs to be carried out to properly address this issue.

Models on plastic distribution and transfer in all marine compartments are needed to provide reliable estimates of marine fluxes from land to sea. These efforts should be strongly encouraged to better drive globally agreed prevention and mitigation strategies to be adopted and harmonized across countries.

\section{CONTRIBUTION TO THE FIELD}

Marine litter is an urgent environmental threat comprising primarily plastic debris. Yet, the global production of plastic is expected to double over the next decades, with envisaged severe impacts across ecosystems and societies. This editorial introduces to the Research Topic "Impacts of Marine Litter", aiming at a better understanding of marine litter impacts from

\section{REFERENCES}

Angiolillo, M. (2019). "Debris in deep water," in World Seas: an Environmental Evaluation, 2nd Edn eds, C. Sheppard. (Cambridge, MA: Academic Press), 251-268. doi: 10.1016/B978-0-12-805052-1.00015-2

Barboza, L. G. A., Cózar, A., Gimenez, B. C. G., Barros, T. L., Kershaw, P. J., and Guilhermino, L. (2019). "Macroplastics pollution in the marine environment," in World Seas: an Environmental Evaluation, 2nd Edn eds, C. Sheppard. (Cambridge, MA: Academic Press), 305-328.

Beiras, R., Bellas, J., Cachot, J., Cormier, B., Cousin, X., Engwall, M., et al. (2018). Ingestion and contact with polyethylene microplastics does not cause acute toxicity on marine zooplankton. J. Haz. Mater. 360, 452-460. doi: 10.1016/j.jhazmat.2018.07.101

Bonanno, G., and Orlando-Bonaca, M. (2018). Perspectives on using marine species as bioindicators of plastic pollution. Mar. Poll. Bull. 137, 209-221. doi: 10.1016/j.marpolbul.2018.10.018

Bour, A., Avio, C. G., Gorbi, S., Regoli, F., and Hylland, K. (2018). Presence of microplastics in benthic and epibenthic organisms: influence of habitat, feeding mode and trophic level. Environ. Pollut. 243, 1217-1225. doi: 10.1016/j.envpol.2018.09.115

Burns, E. E., and Boxall, A. B. A. (2018). Microplastics in the aquatic environment: Evidence for or against adverse impacts and major knowledge gaps. Environ. Toxicol. Chem. 37, 2776-2796. doi: 10.1002/etc. 4268

Casabianca, S., Cappellacci, S., Giacobbe, M. G., Dell'Aversano, C., Tartaglione, L., Varriale, F., et al. (2019). Plastic-associated harmful microalgal assemblages in marine environment. Environ. Pollut. 244, 617-626 doi: 10.1016/j.envpol.2018.09.110

De Sá, L. C., Oliveira, M., Ribeiro, F., Rocha, T. L., and Futter, M. N. (2018). Studies of the effects of microplastics on aquatic organisms: what do we know and where should we focus our efforts in the future? Sci. Total Environ. 645, 1029-1039. doi: 10.1016/j.scitotenv.2018.07.207

Domènech, F., Aznar, F. J., Raga, J., and Tomas, J. (2019). Two decades of monitoring in marine debris ingestion in loggerhead sea turtle, Caretta caretta, from the western Mediterranean. Environ. Pollut. 244, 367-378. doi: 10.1016/j.envpol.2018.10.047 the ecological, ecotoxicological, economic, and social point of view. This Research Topic also aims at proposing new strategies for the prevention, mitigation and monitoring of marine litter. With its 13 published papers, the Research Topic provides new information on the environmental distribution (including sources and sinks) of marine litter across the globe, as well as on the impacts of plastics' associated contaminants to marine micro and macro fauna. It also highlights constraints and priorities for conducting exposure experiments of marine wildlife to plastics, discusses regulation and policy measures for land waste management and litter disposal at sea, and identifies remaining knowledge gaps which should be the focus of future interdisciplinary research and policy interventions.

\section{AUTHOR CONTRIBUTIONS}

All authors listed have made a substantial, direct and intellectual contribution to the work, and approved it for publication.

\section{ACKNOWLEDGMENTS}

We thank all authors, reviewers, and editors that have contributed to this Research Topic.

Eriksen, M., Lebreton, L. C. M., Carson, H. S., Thiel, M., Moore, C. J., Borerro, J. C., et al. (2014). Plastic pollution in the world's oceans: more than 5 trillion plastic pieces weighing over 250,000 tons afloat at sea. PLoS ONE 9:e111913. doi: 10.1371/journal.pone.0111913

European Commission (2008). Directive 2008/56/EC of the European Parliament and of the Council Establishing a Framework for Community Action in the Field of Marine Environmental Policy (Brussels: Marine Strategy Framework Directive. Official Journal of the European Union).

Fossi, M. C., Pedà, C., Compa, M., Tsangaris, C., Alomar, C., Claro, F., et al. (2018). Bioindicators for monitoring marine litter ingestion and its impacts on Mediterranean biodiversity. Environ. Pollut. 237, 1023-1040. doi: 10.1016/j.envpol.2017.11.019

Gall, S. C., and Thompson, R. C. (2015). The impact of debris on marine life. Mar. Pollut. Bull. 92, 170-179. doi: 10.1016/j.marpolbul.2014.12.041

Galloway, T. S., Cole, M., and Lewis, C. (2017). Interactions of microplastic debris throughout the marine ecosystem. Nat. Ecol. Evol. 1, 0116. doi: 10.1038/s41559-017-0116

Geyer, R., Jambeck, J. R., and Law, K. L. (2017). Production, use, and fate of all plastics ever made. Sci. Adv. 3:e1700782. doi: 10.1126/sciadv.17 00782

Hermabessiere, L., Dehaut, A., Paul-Pont, I., Lacroix, C., Jezequel, R., Soudant, P., et al. (2017). Occurrence and effects of plastic additives on marine environments and organisms: a review. Chemosphere 182, 781-793. doi: 10.1016/j.chemosphere.2017.05.096

Hoornweg, D., and Bhada-Tata, P. (2012). What a Waste: A Global Review of Solid Waste Management. Washington, DC: The World Bank, (2012) Available online at: https://openknowledge.worldbank.org/handle/10986/17388

Jambeck, J. R., Geyer, R., Wilcox, C., Siegler, T. R., Perryman, M., Andrady, A., et al. (2015). Plastic waste inputs from land into the ocean. Science 347, 768-771. doi: $10.1126 /$ science. 1260352

Kühn, S., Rebolledo, E. L. B., and Van Franeker, J. A. (2015). "Deleterious effects of litter on marine life." in Marine Anthropogenic Litter, eds. M. Bergmann, L. Gutow, and M. Klages (New York, NY: Springer International Publishing), 75-116.

Lusher, A. L., Hernandez-Milian, G., Berrow, S., Rogan, E., and O’Connor, I. (2018). Incidence of marine debris in cetaceans stranded and bycaught in 
Ireland: recent findings and a review of historical knowledge. Environ. Pollut. 232, 467-476. doi: 10.1016/j.envpol.2017.09.070

Maes, T., Barry, J., Leslie, H. A., Vethaak, A. D., Nicolaus, E. E. M., Law, R. J., et al. (2018). Below the surface: Twenty-five years of seafloor litter monitoring in coastal seas of North West Europe (1992-2017). Sci. Total Environ. 630, 790-798. doi: 10.1016/j.scitotenv.2018.02.245

Ogonowski, M., Gerdes, Z., and Gorokhova, E. (2018). What we know and what we think we know about microplastic effects - a critical perspective. Curr. Opin. Environ. Sci. Health. 1, 41-46. doi: 10.1016/j.coesh.2017. 09.001

PlasticsEurope (2018). "Plastics - the facts 2018. An analysis of European plastics production, demand and waste data" in Association of Plastics Manufacturers and EPRO (Brussels: European Association of Plastics Recycling \& Recovery Organisations, Association of Plastic Manufacturers and European Association of Plastics Recycling and Recovery Organizations), 18.

Rochman, C. M., Browne, M. A., Underwood, A. J., Van Franeker, J. A., Thompson, R. C., and Amaral-Zettler, L. A. (2016). The ecological impacts of marine debris: unraveling the demonstrated evidence from what is perceived. Ecology 97, 302-312. doi: 10.1890/14-2070.1

Rochman, C. M., Tahir, A., Williams, S. L., Baxa, D. V., Lam, R., Miller, J. T., et al. (2015). Anthropogenic debris in seafood: Plastic debris and fibers from textiles in fish and bivalves sold for human consumption. Sci. Rep. 5:14340. doi: $10.1038 /$ srep 14340

Tekman, M. B., Gutow, L., Macario, A., Haas, A., Walter, A., and Bergmann, M. (2019). Alfred-Wegener-Institut Helmholtz-Zentrum für Polar- und
Meeresforschung. Available online at: https://litterbase.awi.de/litter_detail (accessed February 20, 2019).

UNEP (2014). Valuing Plastics: The Business Case for Measuring, Managing and Disclosing Plastic Use in the Consumer Goods Industry. Nairobi: U.N.E. Program.

Walker, T. R., Adebambo, O., Del Aguila Feijoo, M. C., Elhaimer, E., Hossain, T., Edwards, S. J., et al. (2019). "Environmental Effects of Marine Transportation," in World Seas: An Environmental Evaluation, 2nd edn, eds C. Sheppard. (Academic Press), 505-530. doi: 10.1016/B978-0-12-805052-1.00 030-9

Wilcox, C., Van Sebille, E., and Hardesty, B. D. (2015). Threat of plastic pollution to seabirds is global, pervasive, and increasing. Proc. Nat. Acad. Sci. U.S.A. 112, 11899-11904. doi: 10.1073/pnas.1502108112

Conflict of Interest Statement: The authors declare that the research was conducted in the absence of any commercial or financial relationships that could be construed as a potential conflict of interest.

Copyright $\odot 2019$ Galgani, Beiras, Galgani, Panti and Borja. This is an open-access article distributed under the terms of the Creative Commons Attribution License (CC $B Y)$. The use, distribution or reproduction in other forums is permitted, provided the original author(s) and the copyright owner(s) are credited and that the original publication in this journal is cited, in accordance with accepted academic practice. No use, distribution or reproduction is permitted which does not comply with these terms. 